Cadernos de Arquitetura e Urbanismo, v.17, n.20, 2010 
wast

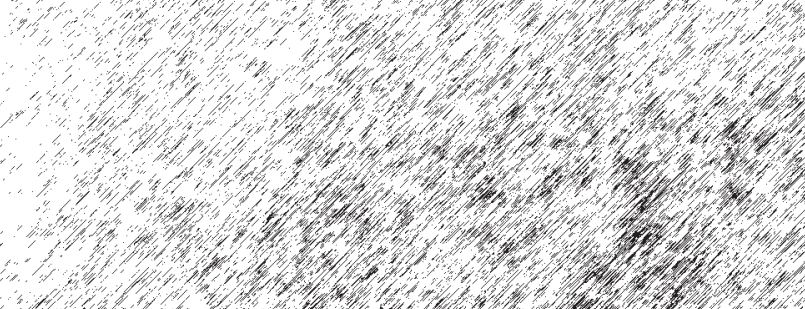

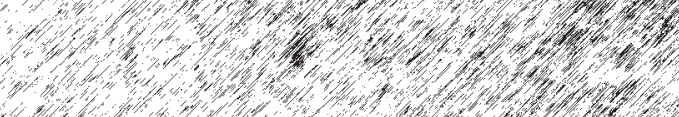
(1)

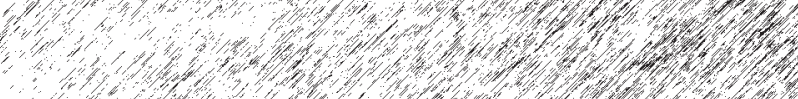
Wy,

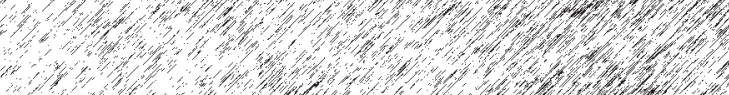

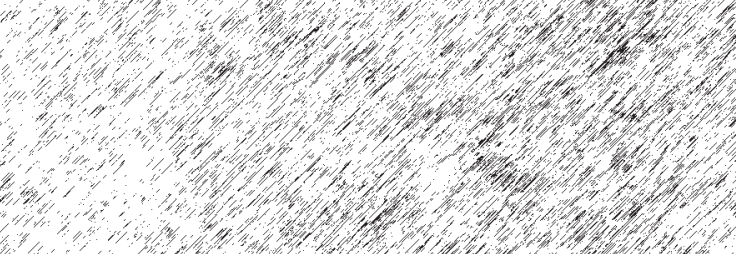
W

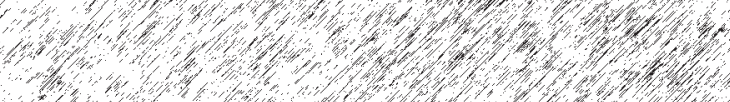

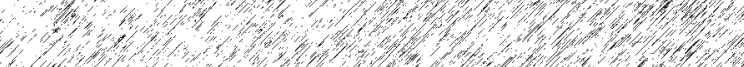

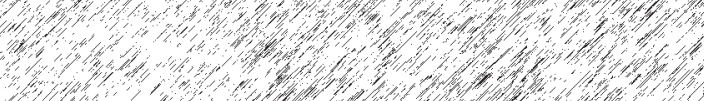

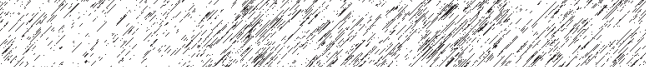

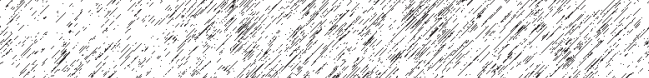

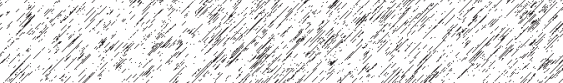

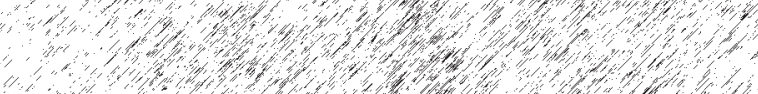

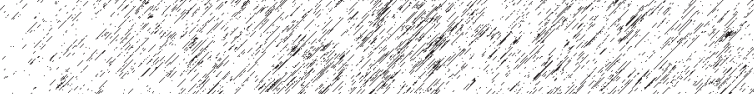
有

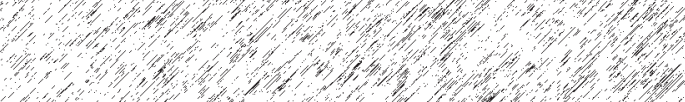

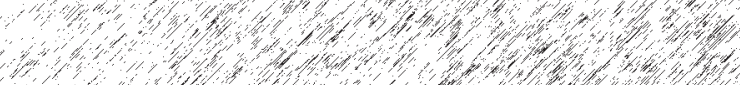

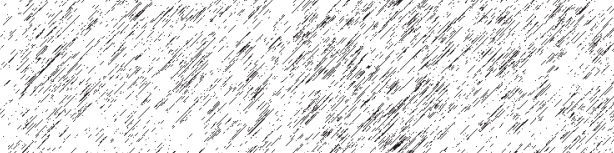
$\%$

$1 / 2$

H, 


\title{
$8^{\circ}$ CIAM: IDEIAS ANTIGAS E UMA NOVA ATITUDE PARA O PLANEJAMENTO URBANO
}

$8^{\text {TH }}$ CIAM: OLD IDEAS AND A NEW ATTITUDE CONCERNING URBAN PLANNING

Angela Martins Napoleão Braz e Silva ${ }^{1}$

\begin{abstract}
Resumo
Com a intenção de revidar as críticas que o movimento modernista vinha recebendo desde o final da II Guerra Mundial, o $8^{\circ}$ Ciam promoveu uma renovação teórica e colaborou para a constituição do campo do urbanismo. Para produzir espaços urbanos adequados a um novo modo de vida, o $8^{\circ}$ Ciam introduziu um método de planejamento baseado na recuperação de centros históricos e na construção de novos centros, e contribuiu para a construção da forma urbana. Por tais feitos cumpre identificar a origem do seu discurso e explicitar o conceito e as influências do método proposto.
\end{abstract}

Palavras-chave: Urbanismo; Forma urbana; Ciam; Planejamento; (Re)centralização urbana.

\begin{abstract}
As a response to the criticism that the modernist movement had received since the end of World War II, the $8^{\text {th }}$ Ciam promoted a theoretical renewal and collaborated to the constitution of the field of urbanism. Aimed at producing urban spaces suitable to a new way of life, it introduced a planning method based on the conservation of historical centers and the construction of new ones, thus contributing to the construction of the urban form. This paper aims to identify the origin of its discourse and explain the concept and influences of the proposed method.
\end{abstract}

Key words: Urbanism; Urban form; Ciam; Planning; Urban centralization. 
2. O primeiro congresso, que ocorreu em 1928 no Castelo de La Sarraz, na

Suíça, registrou a fundação dos Ciams e definiu os seus propósitos: formalizar os princípios da arquitetura moderna e difundi-los. $02^{\circ}$ Ciam ocorreu na cidade de Frankfurt/Alemanha (1929) e tratou da unidade mínima da habitação.

$03^{\circ}$ congresso, realizado na cidade de Bruxelas\Bélgica (1930), teve como tema o aproveitamento racional do lote. $\mathrm{O} 4^{\circ} \mathrm{Ciam}$ ocorreu em Atenas

Grécia (1933) e teve como tema os problemas enfrentados por 33 cidades.

Para solucioná-los, o Ciam criou as

regras da cidade funcional publicadas na Carta de Atenas - consultar Relatório $4^{\circ}$ Ciam (CORBUSIER, 1933). Para conhecer outras interpretações da

Carta de Atenas, consultar: Can our cities survive? (SERT, 1942) e (Outras) Cartas de Atenas (SAMPAIO, 2001). O $5^{\circ}$ Ciam ocorreu em Paris/França (1937) e tratou da moradia e da recreação. $\mathrm{O}$

$6^{\circ}$ congresso, realizado em Bridgwater

Inglaterra (1947), foi uma reafirmação dos objetivos do Ciam. $07^{\circ}$ congresso

se realizou em Bérgamoltália (1949)

e tratou da cultura arquitetônica. $08^{\circ}$ Ciam - tema deste artigo, realizado em Hoddesdon/Inglaterra (1951), promoveu

um estudo sobre centros urbanos, apresentando-os como o "coração das cidades." O $9^{\circ}$ Ciam ocorreu em Aix-en-

Provence/França (1953) e apresentou

o habitat humano como tema. $010^{\circ}$

Ciam se reuniu em Dubrovnik/Yugoslavia

(1956) para tratar do mesmo tema do congresso anterior, entretanto, ao invés

de produzir soluções arquitetônicas esse congresso demonstrou a fragilidade do discurso unitário do Ciam.

Finalmente, em 1959, por causa da postura divergente de seus membros,

o Ciam se dissolveu como grupo de trabalho (MUNFORD, 2002).

3. Sert nasceu em Barcelona (19021983), estudou arquitetura na Escola

de Barcelona. Depois de concluir seus estudos, em 1929, mudou-se para Paris, onde trabalhou com Le

Corbusier. Em 1930 fundou, junto com outros arquitetos, o GATCPAC (Grup

d'Arquitectes i Tècnics Catalans per al Progrés de I'Arquitectura Contemporània) e a partir de 1933 participou do

Ciam, chegando a ser presidente dos Congressos de 1947 a 1956 (do $4^{\circ}$ ao $10^{\circ}$ Ciam). Em 1939 Sert se exilou nos USA, onde exerceu atividades como projetista e professor. Fez projetos para a Europa, USA e América do Sul e foi decano da Universidade de Harvard (Fonte: http:// www.soloarquitectura.com/arquitectos/

josep_lluis_sert.html. Acesso em: 11 maio 2007)

Cadernos de Arquitetura e Urbanismo, v.17, n.20, 2010
Os Congressos Internacionais de Arquitetura Moderna - os "Ciams" - foram grupos de trabalho, sem nacionalidade, criados para discutir o rumo da arquitetura e do urbanismo modernos em meio às rápidas mudanças que ocorriam no mundo. ${ }^{2}$ Pretendiam revolucionar e internacionalizar a arquitetura para que fosse utilizada como uma ferramenta econômica e política aplicada ao desenho de edifícios e cidades. Esse objetivo, de acordo com José Luís Sert ${ }^{3}$ (1955), seria alcançado através de uma sistematização teórica comum no âmbito da arquitetura e do urbanismo. Desde então as questões fundamentais da arquitetura moderna estiveram ligadas aos problemas da urbanística (MUNFORD, 2002).

Este artigo trata da oitava edição do Ciam, realizada na cidade de HoddesdonVnglaterra em 1951. A justificativa para a escolha desse Ciam e não de outro baseia-se no fato de que produziu um método de planejamento que se opunha às práticas e teorias modernistas preconizadas anteriormente. Sua abordagem é feita a partir de alguns questionamentos: quais seriam os problemas que suscitaram as discussões desse Ciam? Quais as bases conceituais do método proposto? De onde surgiram essas ideias? Como foram assimiladas? Em que diferem da prática anterior? Quais as experimentações e especulações teóricas apresentadas? Que reações despertaram? Quais suas consequências em termos de construção da forma e do saber urbano?

Responder a essas questões significa esclarecer o contexto em que ocorreu o $8^{\circ}$ Ciam e verificar o significado de suas consequências em relação às cidades e à construção do campo do urbanismo. Nesse sentido, além de apresentar o método de planejamento proposto pelo $8^{\circ} \mathrm{Ciam}$, este artigo também procura explicitar o conceito no qual se baseia, bem como identificar suas influências e analisar algumas concepções espaciais construídas segundo seus princípios. Por fim, ao questionar a construção do método e suas consequências espaciais, oferece conclusões acerca do papel do urbanista.

\section{O contexto}

Desde sua fundação o Ciam buscou soluções para os problemas gerados pelo crescimento das cidades, tais como: o adensamento populacional em certas áreas urbanas, a insuficiência de moradia e de áreas verdes, moradias localizadas em áreas sem infraestrutura de serviços e sem condições de higiene e de segurança, longas distâncias entre a moradia e o local de trabaIho, a localização de indústrias em áreas habitacionais, ruas com dimensões inadequadas à utilização dos novos meios de transporte, traçados construídos para enfatizar uma perspectiva grandiosa de certos monumentos ou edifícios, e um parcelamento desordenado do solo (CURY, 1995).

A solução para essa problemática surgiu no $4^{\circ}$ Ciam, realizado em Atenas (1933). Desde então o espaço urbano passou a ser planejado com base em alguns princípios, tais como:

- A cidade apresentava quatro funções principais: moradia, trabalho, recreação e circulação;

- A moradia era a célula inicial do urbanismo e a partir dela se estabeleciam os serviços de abastecimento, de educação, assistência e lazer; 
- O planejamento da cidade considerava a região de sua influência econômica ao invés de estudar apenas o território contido por seus limites;

- O ordenamento do território consistia em utilizar a "circulação" para integrar as demais funções urbanas, o que implicava dotar a cidade de uma rede de vias públicas proporcional aos seus usos e fins;

- O interesse privado era subordinado ao interesse coletivo, o que implicava criar espaços livres necessários às comunicações e lazer, explorando-se a dimensão "altura" dos volumes construídos (CURY, 1995).

Mas essa prática foi confrontada pelos novos problemas urbanos surgidos no pós-guerra. Locais urbanos "extintos" por ação da guerra precisavam ser reconstruídos e reconstruir significava problemas nunca antes pensados, tais como lidar simultaneamente com tecidos urbanos historicamente densos e com a necessidade de criar novos espaços de moradia e convivência. Por outro lado, as áreas centrais das cidades europeias se esvaíam sem movimento, permitindo o abandono de seus valores tradicionais, e as cidades nos Estados Unidos passavam pelo processo de "descentralização" provocado pelo crescimento dos subúrbios (GOMES, 2007a). Essa problemática era atribuída à postura do Ciam. Dizia-se que a arquitetura e o urbanismo praticados pelo Ciam estavam levando o indivíduo ao isolamento e que sua concepção urbana não identificava uma estrutura social correspondente.

Para revidar essas críticas, o Ciam buscou rever, em sua oitava edição, alguns aspectos da sua prática urbanística e constatou que certos pontos negativos da forma urbana eram consequência da aplicação da Carta de Atenas. Verificou, por exemplo, que:

- O estruturalismo funcional incorreu na geometrização das cidades e na dificuldade de promover sua legibilidade;

- A arquitetura restrita aos edifícios de caráter utilitário impediu uma reflexão sobre sua aplicação em edifícios públicos:

- A estética excludente, que gerou um distanciamento entre arquitetura, pintura e escultura, resultou em experiências arquitetônicas cujo valor plástico não representava a sociedade contemporânea;

- O aspecto monumental de suas experiências gerou uma relação invariável e apática entre forma construída, espaço e sociedade;

- A dispersão urbana provocada por uma visão tecnicista, ao privilegiar o fluxo do automóvel na estrutura urbana, implicou a expansão territorial (suburbanização) das cidades.

A partir dessas constatações o Ciam repensou seu modo de intervir nas cidades e se propôs a buscar uma harmonia entre a estrutura social urbana e sua estrutura espacial através do retor-

4. Relatório sobre a realização do $8^{\circ} \mathrm{Ciam}$.

Cadernos de Arquitetura e Urbanismo, v.17, n.20, 2010 no das relações sociais como principal condição de projeto. De acordo com Munford (2002), a partir desse momento tem início um novo "capítulo" nas atividades do Ciam. Portanto, o $8^{\circ}$ Ciam é um marco histórico em sua prática. E esse fato pode ser comprovado através da leitura El corazón de la ciudad (SERT, 1955). ${ }^{4}$ Ele demonstra o processo autocrítico que gerou a renovação te- 
órica do Ciam, caracteriza sua nova postura como uma reunião de tendências sobre a forma de repensar a cidade e, mais do que isso, demonstra que o movimento moderno na arquitetura e urbanismo foi marcado por duas características: diversidade formal e universalidade de seu discurso.

\section{O método proposto}

O método de planejamento introduzido pelo $8^{\circ}$ Ciam deveria evitar a desconstrução da sociabilidade urbana que, segundo se dizia, era resultante de sua prática anterior. Portanto, o objetivo principal da metodologia proposta era colaborar para transformar o indivíduo passivo em indivíduo ativo na vida social. Nesse sentido a aplicação do método deveria, segundo Corbusier, criar um espaço que constituísse "uma síntese física da vida social, dando a cada aglomerado urbano os elementos fundamentais de sua economia" (SERT, 1955, p. 39). Significa dizer que em razão de suas atribuições, o lugar deveria funcionar como um espaço onde a comunidade - do bairro ou da cidade - pudesse desenvolver uma rede de relacionamentos e através dela articular a vida urbana. Ou seja, o lugar deveria funcionar como um centro cívico.

A concepção desse espaço deveria partir de alguns princípios muito particulares, em número de cinco, descritos a seguir. $O$ primeiro deles era de ordem conceitual. Dizia respeito à ideia geral acerca da concepção do lugar. Deveria ser um espaço onde as pessoas pudessem se reunir e se manifestar livremente e, independentemente de sua localização e conteúdo, deveria dar ideia de espontaneidade, de liberdade, de movimento. Do ponto de vista perceptivo deveria ser a expressão cultural da sociedade, ou seja, deveria incorporar as marcas de seu passado e as dos dias atuais. Esperava-se dessa forma possibilitar maior contato social entre os habitantes da cidade. O urbanista deveria criar uma atmosfera de descanso e estabelecer uma consciência cívica através da estrutura arquitetônica. O segundo princípio era de ordem funcional. Dizia respeito ao fato de que o lugar deveria ser concebido e executado para ter maior eficácia nas funções próprias da cidade. Isto é, deveria conter a sede das principais atividades de uma comunidade: serviços, diversões, contemplação e ócio. Esperava-se dessa forma atrair os habitantes residentes em seu entorno além de incrementar a animação urbana. Nesse sentido sua estrutura arquitetônica (espaço, mobiliário e decoração) deveria possibilitar a geração de atividades espontâneas, além de abrigar ou simbolizar as atividades da comunidade do ponto de vista social, administrativo e espiritual. O terceiro princípio, de ordem dimensional, dependia da grandeza física do território e de seu povoamento. A quantidade e as dimensões do centro cívico deveriam ser regidas pela proporção numérica da população e pela densidade populacional do território. O quarto princípio, de ordem relacional, era provavelmente resultado do esforço conjunto de Sert, Giedión e Léger em Nine points on monumentality (GIEDIÓN, 1958). Determinava-se que, além de promover a relação social, a estrutura arquitetônica do centro cívico deveria buscar a relação entre monumento e passado e entre a arquitetura e as artes. Esperava-se com isso obter uma relação flexível, adaptável e ativa entre forma construída, espaço 
5. O centro cívico contém dois princípios básicos relacionados à sua centralidade: um geométrico, relacionado ao desenho urbanístico e outro funcional relacionado ao uso que se faz dele. Às vezes eles coincidem, em outras não.

A não coincidência pode ser reflexo das condições topográficas particulares ou de certos fatores sociológicos e históricos.

6. Desde a Carta de Atenas, os veículos e suas velocidades passaram a ser adotados como base das escalas das medidas aplicadas às superfícies e às distâncias.

7. Tradução da autora.

Cadernos de Arquitetura e Urbanismo, v.17, n.20, 2010 e sociedade. O quinto princípio era referente à estrutura formal e aludia à linguagem a ser utilizada na construção do centro cívi$\mathrm{co}$. A regra geral era que o novo espaço pudesse continuamente atender às novas exigências da população (costumes, por exemplo). Para tanto era necessário utilizar o ser humano como módulo e sempre se referir a ele. Tal exigência incorreria em classes diferentes de espaço, tais como espaços abertos ou fechados e em composições com forma geométrica ou livre. O objetivo era obter uma relação harmônica entre a massa edificada e o espaço livre entre elas para dessa forma evitar a monumentalidade tão criticada por Giedión (1956) e outros.

Assim se constata que o método previa a criação de um lugar cuja concepção espacial deveria apresentar três características básicas:

- Um núcleo espacial ${ }^{5}$ como local propício à prática social,

- Uma monumentalidade como representação da identidade, da imagem e história da estrutura social e

- Uma interação da arquitetura com as artes para refletir os valores e desejos da sociedade contemporânea.

- A base conceitual do método

Mas onde o $8^{\circ}$ Ciam encontrou argumentos para construir a metodologia proposta?

O relatório El corazón de la ciudad (SERT, 1955) evidencia que a produção espacial do centro cívico deveria buscar a humanização do ambiente através da afirmação dos direitos do indivíduo e do retorno da medida humana como unidade da escala de projeto, pois ambos foram preteridos na modernização das cidades e substituídos pelos veículos automotores e suas novas velocidades. ${ }^{6}$ Com essa intenção, o Ciam buscou uma unidade espacial que fosse significativa para a cidade em termos de convivência social. Buscando essa unidade espacial, Sert, Giedión e outros integrantes do Ciam recorreram à história e constataram que a forma urbana das cidades antigas proporcionava uma vida aprazível:

No passado muitas cidades tinham formas e estruturas definidas e estavam construídas em torno de um núcleo central que, amiúde, era o fator determinante daquelas formas. Eram as cidades que faziam seus núcleos, porém estes à sua vez faziam da cidade uma verdadeira cidade e não simplesmente um aglomerado de pessoas. O núcleo ou centro, que aqui chamamos El Corazón, é o elemento essencial de todo verdadeiro organismo. (SERT, 2007, p. 6) ${ }^{7}$

Significa dizer que os membros do Ciam perceberam as áreas centrais das cidades antigas como espaços significativos que, além de determinar a forma urbana, também eram impregnados de um sentido de comunidade fortemente percebido em sua apropriação. Segundo Sert (1955), esses lugares foram exemplo de beleza e de facilitação de encontros sociais, portanto merecedores do interesse dos modernistas em utilizá-los como base conceitual do novo método de intervenção nas cidades.

Com esses argumentos o sentido de comunidade foi introduzido como ideia norteadora para a organização das distintas fun- 
8. O termo "coração" é discutível para aqueles que veem a cidade como uma estrutura de relações espaciais e não um "ser vivo" como queriam os modernistas. Por considerar que a centralidade do espaço idealizado no $8^{\circ}$ Ciam é função da animação urbana proporcionada pela estrutura

de relações espaciais e não resultado do "assentamento de sentimentos humanos" (GIEDIÓN, 1958), sabendo-se que é a organicidade e a flexibilidade da estrutura urbana que determinam a convergência de movimentos para determinada área, conferindo-lhe centralidade metafórica ou geométrica; e considerando que devido à similitude de significado com sua base conceitual, acredita-se que o termo "centro cívico" seja mais adequado para nominar o método criado no $8^{\circ}$ Ciam.

9. Tradução da autora.

10. A poluição ambiental deveria ser subtraída ao tempo em que o paisagismo deveria harmonizar-se com os edifícios em termos de formas arquitetônicas, materiais e cores utilizadas.

11. Publicado em Plastique, editado por Sophie Tauber-Arp, n. 1, Paris, 1937.

12. Prefácio para o escultor Bem Nicholson, Londres, 1937.

13. Publicado por Paul Zucker em New architecture and city planning (Nova York, 1944) e Sert (1955).

14. Acredita-se que a referência de Giedión à separação de fluxos se deve ao fato de a preservação da acessibilidade do pedestre ser um dos fundamentos próprios do urbanismo moderno

Cadernos de Arquitetura e Urbanismo, v.17, n.20, 2010 ções em uma zona urbana ou para a criação de um novo setor urbano ao qual se denominou centro cívico, lugar que, no debate do desenho das cidades, significa sua centralidade simbólica, ou como diziam os modernistas, o "coração" de sua estrutura urbana. $^{8}$

[...] um centro pluriforme e de máximo alcance social [...] lugar físico no qual encontram assento os sentimentos humanos mais elevados e mais necessários para a plenitude de uma arquitetura em busca de um novo humanismo. (GIEDIÓN in SERT, 1955, p. 162) ${ }^{9}$

O sentido de comunidade, base conceitual do método, deveria se revelar no padrão de convivência de cada centro, através da realização de atividades relacionadas às oportunidades de negócio, serviços públicos, educação, lazer, cultura e interação social (SERT, 1955). E independentemente de sua situação geográfica e topográfica, o centro cívico deveria apresentar certas características relacionadas à apropriação que em última instância também definiria seu aspecto formal. Dentre algumas dessas características estão: a obrigatoriedade da implantação dos edifícios públicos, da separação absoluta entre pedestre e veículos, da utilização de distâncias facilmente percorridas a pé, da harmonia ambiental com a tipologia do entorno, ${ }^{10}$ de lugares e circulações protegidos das intempéries e de dimensões calculadas em função das atividades oferecidas.

Entretanto, a construção da base conceitual se fez sobre ideias que não eram novas. A preocupação em preservar e estimular a convivência social aparece em artigos de Giedión, anteriores à realização do $8^{\circ}$ Ciam. Entre esses artigos estão: "Necessitamos de artistas?",11 "A arte como chave da realidade,"12 "Sobre uma nova monumentalidade".13 Essa mesma ideia também aparece em 1945, em artigo de Walter Gropius sobre a reconstrução das cidades e em projeto de Corbusier para o centro comunal de St. Dié (SERT, 1955). Diante da importância que os modernistas atribuíram à ideia de "vida em comunidade", justifica-se obter maiores informações sobre sua procedência. Qual seria sua origem na arquitetura e no urbanismo?

A leitura de Giedión, principalmente em Arquitectura y comunidad (1958), permite identificar que algumas das ideias sobre convivência social haviam sido exploradas anteriormente. O autor indica que desde 1857 há registros de concepções espaciais onde se percebe a inclusão desse sentido de comunidade através da utilização de alguns artifícios arquitetônicos. Cita como exemplo a separação de fluxos (pedestres/veículos) utilizada por Frederick Law Olmsted nas passagens subterrâneas do projeto do Central Park em Nova York e por Ebenezer Howard nas cidades-jardins. Constata-se que em ambas as concepções os fluxos foram separados no intuito de preservar a acessibilidade do pedestre e assim facilitar os encontros sociais. ${ }^{14}$

A manifestação de outros elementos inerentes à convivência social e que compõem o método proposto pelo Ciam pode ser observada na cultura arquitetônica e urbanística. A preservação da história da sociedade através da manutenção de elementos construídos que sejam significativos para a sua identidade e imagem (principal característica do centro cívico) é uma preocupa- 
15. Tal assertiva é construída a partir de elementos fornecidos por Marco Aurélio Gomes em Arte urbana e urbanismo: heranças e reinterpretações na constituição do campo disciplinar (2007a) e da leitura de Françoise Choay em ensaio escrito como prefácio do catálogo de uma exposição do Centro Pompidou (CHOAY,

1996) e em O urbanismo, utopias e realidades - uma antologia (2007), onde Choay revê a obra de 37 autores.

16. Pöete (1866-1950): historiador, arquivista e bibliotecário francês.

Throughout his life, he was interested in the evolution of the urban plan,

studying especially the morphological transformations of Paris. Ao longo de sua vida esteve interessado na evolução do plano urbano, tendo estudado principalmente as transformações morfológicas de Paris, sobretudo a ocupação dos espaços livres, as zonas de crescimento da cidade e as reconstruções

em concordância com a legislação de

1919 (Planning perspectives. v. II, n. 4. London: Routledge, 1996).

17. Giovannoni (1873-1943): historiador, crítico, urbanista, arquiteto e engenheiro

italiano, desde 1913. Em seus estudos se dedicou à cidade moderna. Em Teoria

da restauração, publicado em 1931,

Giovannoni trata dos centros históricos,

da expansão urbana e dos planos

reguladores. Estes, em sua ótica, não

limitavam a cidade apenas aos centros

históricos. Para maiores informações

ver: Maria Piera Sette II restauro in architettura, UTET, Torino, 2001.

18. Em relação ao urbanismo, convém abrir um parêntese para ressaltar

certas nuances de se construir em um contexto atual com base em informações apreendidas no passado (HUYSSEN,

2000). Nesse caso a construção de um espaço é sempre uma reconstrução com base no contexto de uma época e, portanto, corre-se o risco de construir um cenário com apropriação limitada.

Na verdade, a história como método

de pensar consiste em uma leitura ou interpretação e, portanto, nunca será absolutamente neutra. Significa dizer que sua utilização aplicada na construção

da cidade exigirá do arquiteto uma interpretação contemporânea. Ele deverá evitar a prática cenográfica (edifícios novos em estilos antigos, por exemplo).

19. Característica do método de planejamento que estabelece a possibilidade de algumas unidades sociais terem mais de um centro cívico em função da densidade demográfica e da superfície do território a sofrer intervenção.

Cadernos de Arquitetura e Urbanismo, v.17, n.20, 2010 ção recorrente na história intelectual do planejamento urbano do século XX. Ela surge, por exemplo, com Cerdá em seu Plano de Barcelona, quando relaciona o centro histórico com o território do entorno, demonstrando consideração quanto às preexistências (HALL, 2002), e é percebida em Patrick Geddes (Cidades em evolução), quando relaciona a cidade ao meio físico e à sua história.

A base conceitual do centro cívico também encontra respaldo entre ideias e propostas veiculadas em época anterior aos Ciams. ${ }^{15}$ É o caso, por exemplo, da preservação das preexistências e sua relação com a identidade e a imagem da sociedade, observadas em trabalhos de Marcel Pöete ${ }^{16}$ e Gustavo Giovannoni. ${ }^{17}$ Pöete desenvolveu um método de estudo da cidade onde procurava relacionar a história da cidade à sua imagem e às suas ligações com o sítio. Para ele, a forma da cidade condensa sua história. Giovannoni defendia ideias semelhantes à de Pöete: para ele, os valores culturais de uma cidade deveriam se relacionar com sua modernização (SERT, 1955). Significa dizer que, para Giovannoni, o propósito de fazer planejamento urbano implica estabelecer um diálogo entre a cidade contemporânea e sua história.

Três aspectos indicam que os modernistas bem que poderiam ter se apoiado em Pöete e Giovannoni para construir o seu discurso em prol da utilização do centro cívico. O primeiro se refere ao fato de Pöete como Giovannoni terem baseado seus estudos nos centros históricos por julgar que o entendimento dessas áreas permitiria identificar um princípio gerador e regulador que pudesse ser aplicado na concepção de novas intervenções urbanas (CHOAY, 1996). Pelo mesmo motivo - a busca de um princípio gerador, o centro histórico também foi objeto de interesse do Ciam, pois se observa que o seu discurso se faz na direção de uma informação histórica - a área central das cidades antigas. O segundo decorre do entendimento de que Giavannoni e Pöete percebiam a história como um repositório da forma urbana, onde o espaço vivido é manifestação concreta da história, percebida apenas como memória. Nesse caso pode-se afirmar que Giavannoni e Pöete consideravam a história como responsável pela construção da cultura. Os modernistas também a viam dessa forma, pois a utilizavam como matéria cultural na aplicação do método do $8^{\circ}$ Ciam. Entretanto, diferentemente das concepções de Giavannoni e Pöete, constata-se que na concepção modernista a história também é utilizada como uma "forma de pensar" para esclarecer as inquietações do presente. A contextualização da problemática urbana era feita com base em informações do passado e isso significa dizer que os modernistas também percebiam a história como um método de trabalho. ${ }^{18}$ O terceiro aspecto está relacionado à forma como Giovannoni e Pöete percebem o ordenamento da cidade. Depreende-se de suas concepções que a intervenção na cidade contemporânea deveria considerar o conjunto do patrimônio urbano antigo de forma fragmentada (CHOAY, 1996). Giovannoni foi o primeiro a tratar o planejamento urbano sob uma ótica fracionada em local e territorial (SERT, 2005). Essa forma de ver a ordenação espacial é, aparentemente, a base da visão que os modernistas tinham da cidade. Ela se evidencia através do 'terceiro princípio - dimensional'19 cuja prescrição permite inferir a cidade constituída por 
20. Hampstead, localizada ao norte de Londres, foi imaginada inicialmente como uma comunidade. Não era prevista como autônoma, configurava-se apenas como um subúrbio da capital inglesa.

21. Unwin também escreveu Nothing by overcrowding (1912). Trata-se de uma reflexão histórica sobre a forma urbana em face do empobrecimento estético e qualitativo e da uniformização observada na produção recente (à época) de cidades e bairros, que também foi tema de discussão no $8^{\circ}$ Ciam.

22. Curiosamente o livro de Sitte foi publicado nos Estados Unidos pela primeira vez em 1945, pouco tempo antes da realização do $8^{\circ} \mathrm{Ciam}$.

Cadernos de Arquitetura e Urbanismo, v.17, n.20, 2010 zona rural, bairro, distrito e região. Isso é ou não uma visão da cidade fragmentada em sua ordenação espacial?

Além das semelhanças com o pensamento de Giovannoni e Pöete, parece que o $8^{\circ}$ Ciam também buscou inspiração nas ideias de Raymond Unwin (1863-1940) e em Camillo Sitte (1843-1903), com este último caso se considere o trabalho de Renato Rêgo (2007).

Segundo Rêgo (2007), Unwin construiu uma proposta padrão de organização espacial da sociedade do ponto de vista do território, a partir de uma reinterpretação da cidade-jardim de Ebenezer Howard (1850-1928). A proposta de Unwin era baseada na relação campo/cidade, na morfologia e na pequena escala, e apresentava uma hierarquização das partes do desenho da cidade, enfatizando algumas delas e subordinando outras. Unwin conseguiu essa hierarquização através da inclusão de centros bem definidos na forma urbana. Essa proposta de organização espacial, utilizada por Unwin e seu sócio Barry Parker nas cidades-jardins de Letchworth e Hampstead, ${ }^{20}$ foi publicada em 1909 (Town planning in practice ${ }^{21}$ sob a forma de um manual de desenho urbano com soluções formais e sugestões de procedimentos para o desenho da cidade. Entre elas: o desenho informal de ruas; configurações geométricas menos rígidas; convívio com a natureza; ambiente acolhedor e pitoresco; o homem como unidade de medida da escala projetual; a definição formal da praça; a relação centro da cidade/praça/estação ferroviária; o modo de agrupar os edifícios públicos e sua posição em relação à praça central; a determinação do centro principal e a escolha dos centros secundários em correta proporção e relação com ele; a organização da rede principal de ruas em relação e proporção adequada com os centros principais e secundários que dividem a cidade em diversas zonas; a definição das principais linhas de comunicação entre cada centro, entre o centro principal e o subúrbio que o rodeia, entre as áreas residenciais e os núcleos de comércio ou emprego; o ajardinamento diferenciado das vias; os cruzamentos de vias e certas dimensões recomendadas para as quadras e os lotes (RÊGO, 2001).

A leitura de El corazón de la ciudad nos indica que o centro cívico parece conter as orientações de Unwin. As concepções espaciais apresentadas no $8^{\circ} \mathrm{Ciam}$ demonstram que a construção do espaço de convivência social envolveu algumas preocupações estéticas cujas soluções formais permitem inferir a aproximação dos modernistas com o pensamento de Unwin e com as ideias de Sitte sobre a vida em comunidade. ${ }^{22} \mathrm{~A}$ comunhão de ideias transparece principalmente no que se refere à consideração das preexistências como base para o projeto, ao traçado consoante com as características naturais do terreno, à presença maciça do verde como elemento de composição do espaço urbano, ao caráter artístico da malha urbana (em especial o efeito do traçado regular da área central), à forma das praças, à composição bucólica de edifícios e espaços públicos fechados, à estrutura de bairros e centros, à caracterização das vias e à valorização da individualidade urbana a partir das particularidades de cada contexto.

Dentre as concepções elaboradas segundo o centro cívico e que permitem estabelecer uma relação entre sua base conceitual e as cidades-jardins de Sitte e o processo de centralização de Unwin, estão: os planos urbanísticos de Sert e Wiener para a 
23. Plano Diretor de Medellín, Colômbia (1949); Propostas para o habitat tropical em Tumaco, Colômbia (1949); Urbanização de La Pomona, Venezuela (1951); Projeto Igreja em centro cívico de Puerto Ordaz, Venezuela (1951);

Plano diretor de Bogotá, Colômbia (1951-1953) e o Plano Piloto de Havana, Cuba (1955-1958) (Fonte: http://www. soloarquitectura.com/arquitectos/josep_ lluis_sert.html).

24. O historiador Eric Munford (2000) entende que a primeira fase do Ciam foi de influência da Bauhaus e se desenvolveu predominantemente na Europa. A segunda fase foi centrada em Le Corbusier, arquiteto francês que difundiu suas ideias além das fronteiras francesas e europeias. A terceira

fase compreende o período posterior

à Segunda Guerra Mundial, que se caracterizou por tentativas de responder às críticas que sua prática recebia.

25. O país atraía urbanistas europeus fugidos da guerra ou em constantes visitas, seja como técnicos contratados ou para participar de eventos da categoria. No caso do Ciam, por exemplo, o Conselho Diretor de sua oitava edição era composto por grande número de arquitetos europeus radicados nos Estados Unidos: Giedión, Sert, Mies Van de Rohe, dentre outros (GOMES, 2007a).

26. O planejamento nos Estados Unidos era fundamentado no capitalismo, tinha pouca ou nenhuma carga utópica, e sua arquitetura era desvinculada do contexto

físico e histórico (VENTURINI, 2003).

27. Referência à indefinição entre o espaço público e o espaço privado.

28. Outra forma de perceber e conceituar espaços consiste em fazer estudos analíticos e descritivos do comportamento dos usuários em seu cotidiano

Cadernos de Arquitetura e Urbanismo, v.17, n.20, 2010
América do Sul, realizados entre 1948 e 1958, ${ }^{23}$ e os planos de Corbusier realizados para a reconstrução de St. Dié (França) e a construção de Chandigarh, capital de Punab (Índia).

Os planos de Sert e Wiener para a América do Sul representam os primeiros exemplos de aplicação do método de reorganização e crescimento das cidades proposto pelo Ciam. Dentre seus projetos, os planos de Calli e Medellín se tornaram importantes porque determinam o início da planificação das cidades na Colômbia (GIEDIÓN, 1958). Entretanto seu projeto para a construção da cidade industrial de Chimbote (Peru) e o projeto de Corbusier para a reconstrução de St. Dié (França) são considerados as principais concepções modernistas desse período, tendo em vista que contêm todas as orientações relacionadas ao centro cívico (SERT, 1955).

\section{As consequências}

El corazón de la ciudad demonstra que, além de buscar um novo mercado de trabalho, o Ciam em sua terceira fase ${ }^{24}$ tentou estabelecer uma nova base para sua arquitetura (MUNFORD, 2002) a partir das críticas sobre as consequências urbanas de sua prática e da necessidade em enfrentar novos problemas urbanos nas cidades europeias e nos Estados Unidos. Nesse último país, o Ciam tinha encontrado um campo fértil para suas realizações profissionais, ${ }^{25}$ mas, para se adequar a esse novo mercado de trabalho, precisava assimilar algumas características do planejamento americano. ${ }^{26}$ Essa necessidade de certa forma influenciou a temática do $8^{\circ}$ Ciam e contribuiu para a mudança de foco em relação aos congressos anteriores: os espaços de ninguém ${ }^{27}$ foram deixados de lado para explorar os espaços com função social, a habitação mínima aparentemente foi preterida pela preocupação com o macroespaço coletivo, e todas as discussões tiveram como objetivo dar mais qualidade à vida em comunidade (SERT, 1955).

O modus operandi do $8^{\circ}$ Ciam foi uma reflexão crítica calcada nas obras dos seus membros mais expressivos, como Corbusier, Sert, Giedión, Walter Gropius e Neutra. Esse fato, aliado à mudança de temática, prenunciava que experiências profissionais poderiam constituir base sólida para o estudo da percepção e conceituação dos espaços no urbanismo. ${ }^{28}$ Essa reflexão permitiu ao $8^{\circ}$ Ciam construir um método de planejamento baseado na reconstituição da área central da cidade e na criação de novos centros (SERT, 1955) com o objetivo de produzir uma arquitetura que se pretendia símbolo da identidade urbana e marco da vida social, política e econômica de cada comunidade.

Entretanto, o centro cívico tem um caráter diacrônico: a) sua base conceitual (o padrão de vida comunitária) não é sua propriedade, pois Sitte, Unwin, Ebenezer e outros já o haviam utilizado no passado; b) sua ideia de "centro urbano" não é uma novidade, pois se refere a espaços comuns às cidades desde a antiguidade (ágora grega, praças, parques ou espaços como os então existentes nas grandes cidades: os cafés em Paris, Las Ramblas em Barcelona, Picadille Circus em Londres, Praça Colonna em Roma etc.); e c) seu instrumental teórico não é uma criação do Ciam, pois já era utilizado por projetistas anteriores aos modernistas. 
29. Essa produção habitacional data da segunda metade do século XX, com maior concentração nas décadas de 1960 a 1980

Cadernos de Arquitetura e Urbanismo, v.17, n.20, 2010
Mas em que pese essa diacronia, o centro cívico tem um aspecto meritório. O método de planejamento do Ciam deve ser visto positivamente, na medida em que ofereceu subsídios à prática urbanista em qualquer lugar do mundo, inclusive em nossas cidades contemporâneas. Essa particularidade reafirma um de seus objetivos: a difusão do conhecimento arquitetônico. Mas a universalização de sua prática urbanística, apesar da criatividade de cada arquiteto, do respeito às particularidades locais e da adequabilidade de alguns centros cívicos ao fim que se propunha, gerou certa uniformidade na aparência das cidades. Esse fato pode ser verificado através da presença de alguns aspectos compositivos, tais como: geometria do zoneamento, classificações racionais, coercitividade institucional, tendência de unificar o aspecto das cidades sob influência da estandardização dos elementos construtivos e certa repetição das soluções urbanísticas, o desenho com configurações geométricas menos rígidas, a utilização de uma escala em que o homem era o módulo, a definição formal da praça em geral retangular, a relação obrigatória entre centro da cidade, praça e monumentos, certo modo de agrupar os edifícios públicos e sua posição em relação ao espaço livre, a determinação do centro principal e a escolha dos centros secundários em correta proporção e relação com ele, o ordenamento das vias de circulação em relação e proporção adequada com o centro, a presença do verde e o ajardinamento nos espaços livres destinados aos pedestres como elemento de composição do espaço urbano, o traçado consoante com as características naturais do terreno, o caráter regular do traçado na área de entorno ao centro.

Diante da difusão de sua prática pelo mundo, pergunta-se: qual o impacto que o centro cívico causou às cidades? A resposta a esse questionamento implica a discussão de alguns aspectos do método de planejamento produzido no $8^{\circ} \mathrm{Ciam}$.

O primeiro deles é que o método propõe o centro cívico como marco arquitetônico representativo de uma sociedade. Como tal traz subentendida a ideia de que os centros também deveriam contribuir para consolidar a economia e os regimes de governo de cada lugar. Portanto, a responsabilidade por sua execução e manutenção caberia ao governo existente. Essa relação entre espaço e governo revela uma faceta do centro cívico bastante discutível, porque a organização da arquitetura por certo poder e sua utilização como meio de propaganda podem representar um problema de ordem social e espacial, principalmente se for considerado o possível conflito de seus propósitos com os interesses de certos regimes, caso do capitalismo, por exemplo. Diante dessa consideração, cabe a pergunta: como se comporta uma área criada segundo os princípios modernistas em regimes de governo capitalista? Como é a sobrevivência de suas particularidades formais e funcionais?

Tema recorrente na literatura contemporânea, a avaliação pósocupação na área da habitação popular pode esclarecer tais questões. Parte significativa da produção habitacional de interesse social ${ }^{29}$ promovida pelo Estado brasileiro, sob a tutela do antigo Banco Nacional de Habitação - BNH, por exemplo, é resultado da aplicação das ideias modernistas. Em geral esses conjuntos apresentavam áreas de convivência social, aparentemente pla- 
30. À exceção da proposta feita para Oslo (Noruega), não se veem quaisquer referências à habitação nas prescrições do "centro cívico". nejadas ao modo do centro cívico, que por sua centralidade ou funções teriam um importante papel integrador, mas como regra geral essas áreas se transformaram, perderam certas particularidades formais e funcionais e adquiriram outras para comportar atividades diferentes (BRAZ, 2004). Presentes na maioria das cidades brasileiras, esses conjuntos populares foram responsáveis por modificações importantes na forma urbana dessas cidades e em sua estrutura social, política e administrativa. Além desse feito, também contribuíram para divulgar a ideologia do governo dominante - no caso brasileiro, principalmente o governo exercido por militares (BRAZ, 2004).

Um segundo aspecto se refere ao fato de que o método propõe o centro cívico como "o lugar" para onde todas as pessoas deveriam convergir. Dessa característica se subentende que a massa social era responsável por garantir a sobrevivência do lugar. Da leitura de El corazón de la ciudad se deduz que as possibilidades de uso do centro cívico, embora pensadas em termos globais, têm sua sobrevivência a cargo de sua monumentalidade e interação com as artes (SERT, 1955; GIEDIÓN, 1958). Significa dizer que sua condição de espaço "atrator" de pessoas e movimento parece ser fruto apenas das atividades que oferece. Diante dessa particularidade, percebe-se uma dissociação entre o centro cívico e sua área de entorno, pois parece que a prescrição de suas atividades desprezava a influência da área do entorno quanto à capacidade de também produzir movimentos. Considerando que a mudança das necessidades sociais é um processo urbano intermitente, o centro cívico não poderia ser impermeável ao entorno. Ao contrário, caso suas atividades perdessem a capacidade de atrair, ajustes funcionais deveriam estimular movimentos advindos dos setores urbanos localizados no entorno para dessa forma garantir a sobrevivência do espaço. Esta pode ser a explicação para o esvaziamento contemporâneo de áreas construídas nos moldes do método modernista.

Em paralelo, a aparente desconsideração dos setores urbanos na projetação do centro cívico permite inferir certo esquecimento da habitação, até então alvo da preocupação dos modernistas. ${ }^{30}$ Constata-se que a metodologia introduzida pelo Ciam priorizava os aspectos cívicos e culturais da quinta função da cidade em detrimento das quatro funções preconizadas na Carta de Atenas. No planejamento do centro cívico as quatro funções passaram a ser consideradas apenas como um aspecto na ocupação do terreno em face da resolução de zoneamentos e de planos. Significa dizer que, apesar da intenção de promover a integração social, a desarticulação com a zona residencial do entorno pode explicar as razões pelas quais o centro cívico não teve tanta repercussão quanto à materialização física das unidades de vizinhança, que influíram de forma determinante na habitação de interesse social e no traçado e expansão urbana das cidades (GIEDIÓN, 1958).

Outro aspecto significativo do método proposto é que ele apresenta resquícios de alguns desvios próprios da segunda fase do Ciam. Percebe-se que em geral os centros cívicos são espaços simplistas que tentam manter características corbusianas, como o racionalismo funcional e certo determinismo ao estilo de Unwin e Sitte (FRAMPTON, 2003). Em consequência, e apesar dos bons propósitos, verifica-se que o método não conseguiu 
31. Essa conclusão foi constatada in loco durante experiência da autora como chefe do Setor de Atendimento ao Mutuário, departamento responsável por elaborar projetos de reformas de habitações e áreas livres dos conjuntos construídos pela Cohab-PI

32. O Monumenta é um programa estratégico do Ministério da Cultura para conservação (recuperação e preservação) de áreas urbanas históricas protegidas pelo Instituto do Patrimônio Histórico e Artístico Nacional (Iphan) através do desenvolvimento econômico e social.

Cadernos de Arquitetura e Urbanismo, v.17, n.20, 2010 imprimir vitalidade urbana aos centros cívicos e tão pouco resolveu a expansão e dispersão urbanas para as quais foi criado. Considera-se que a ausência de vitalidade pode ser consequência de o método não contemplar a apropriação espontânea inerente às atividades autônomas, tais como o comércio ambulante, o comércio em quiosques (bancas de jornal, por exemplo) ou o costume de prolongar o comércio até a rua (balcões e mostruários nas calçadas). E em relação à expansão e dispersão urbanas, acredita-se que sua ocorrência se deva ao fato de a aplicação do método demandar um redesenho da cidade que em geral colaborava para sua extensão territorial, haja vista que a implantação do centro ocorria preferencialmente em terrenos livres ou com ocupação rarefeita. O que é isso senão a comprovação de que os modernistas continuavam a promover a expansão das cidades?

A suburbanização é muitas vezes atribuída à prática do Ciam. Muitos bairros populares das cidades brasileiras contemporâneas são oriundos de grandes conjuntos habitacionais planejados segundo o preceito modernista. Construídos para promover a inclusão social de certa população da cidade, esses conjuntos habitacionais eram erguidos em áreas periféricas da cidade, onde o custo do terreno era mais barato. O provimento de condições urbanas para se viver com qualidade na cidade era a característica comum de seus projetos. Significa dizer que o partido adotado consistia em conferir à área uma valorização urbanística que se traduzia em certos princípios, segundo os quais os valores da cidade se fundamentam em noções de eficácia, higiene, saúde, espaços abertos, áreas verdes etc. Do que estamos falando? Dos mesmos princípios da Carta de Atenas.

Em geral esses bairros populares dispõem de equipamentos comunitários implantados de forma concentrada em torno de lou em) uma praça, onde se percebem claramente muitas das características formais do centro cívico. Em relação à sua projetação, certamente em um primeiro momento seus projetistas tinham a intenção de proporcionar um espaço para as pessoas interagirem socialmente: em tese a praça deveria ser lugar de manifestações esportivas, festivas, comemorativas e políticas. Mas em um segundo momento, quando a cidade assimila o espaço produzido, o determinismo arquitetônico e o racionalismo funcional aplicados ao projeto acabam por gerar condições para que se torne um espaço marginal. ${ }^{31}$ Hoje os centros cívicos desses bairros populares se transformaram em áreas segregadas e deterioradas. Sua degradação, que dificulta a animação urbana e às vezes a impede, é atribuída ao Estado, que tem dificuldades em prover sua manutenção, seja por deficiência de quadro funcional ou por dificuldade em obter verbas necessárias.

A par de suas manifestações nos subúrbios contemporâneos, a aplicação de princípios do centro cívico também se manifesta em áreas centrais das cidades. No caso brasileiro, por exemplo, manifesta-se através do projeto Monumenta, ${ }^{32}$ em cujo resultado concreto se observa certo insucesso em termos de uso, pois a questão da revitalização dos centros históricos se polariza entre opostos. De um lado é vista como estratégia de preservação e revalorização de tecidos urbanos degradados das cidades, e de outro é vista como processo de gentrificação, que expulsa os habitantes historicamente enraizados e transforma os cen- 
tros históricos em simulacros da vida tradicional voltados aos turistas. Essas áreas invariavelmente se transformaram em cenários de um passado subjetivado, reinterpretado e distante da realidade contemporânea. Citem-se como exemplo alguns casos brasileiros: os centros históricos do Recife (Bairro Bom Jesus), São Luís e Salvador (Pelourinho) ou ainda os conjuntos urbanos que envolvem praças e edifícios como a Praça Pedro II, o Teatro 4 de Setembro e o Clube dos Diários em Teresina, a Praça da Sé e a Estação da Luz em São Paulo, ou a Praça XV e a Estação das Barcas no Rio de Janeiro.

Quando a reconstrução intenta a reabilitação - caso de praças localizadas de forma pulverizada na cidade - não se consegue evitar o esvaziamento dessas áreas, agravado pelo enclausuramento do espaço, que de certa forma se justifica porque as autoridades precisam proteger o patrimônio público da ação de marginais. Há ainda a mudança de objetivos imputada a essas áreas e que exige sua adequação às novas necessidades. Enclausuramento e mudança de objetivos em geral diminuem a qualidade da área e dificultam a vida em comunidade. Muitas praças se transformam, por exemplo, em áreas para estacionamento de veículos e depois se constata que tal reconstrução, além de não estimular a apropriação, traz outro problema que a torna mais difícil.

Essas áreas das cidades, centros históricos ou praças pulverizadas, desprovidas do "olhar das ruas" em certos momentos do dia, apresentam altos índices de criminalidade que dificultam ou inviabilizam sua apropriação depois de reconstruídas. Trata-se de um paradoxo: embora valorizadas urbanisticamente, não são atraentes do ponto de vista do uso. Sem animação urbana, não retratam o modo de vida procurado pelos modernistas do Ciam e pelos urbanistas contemporâneos. Hoje a praça, em alguns casos, é até vista como um problema. São apenas planos abertos no jogo dos cheios e vazios da cidade. São meros instrumentos de ventilação urbana e de modo geral têm atividades incompatíveis com as necessidades do entorno.

No entanto acreditamos que o Ciam não pode sozinho levar a culpa por tudo que se produziu de ruim em matéria de arquitetura nos últimos cinquenta anos. Há de se considerar que os desvios de sua arquitetura também devem ser creditados àqueles - autoridades públicas e especuladores - que, ao se apropriarem de forma indevida dos princípios modernistas, acabaram por gerar espaços inadequados do ponto de vista artístico e funcional. Hoje, do ponto de vista urbanístico, parece que alguns desses lugares já não têm solução na cidade contemporânea. O que fazer com eles? Esse é um problema cuja solução exige a valorização dessas áreas em uma perspectiva de novas formas de organização social e de desenho.

E é esta dúvida - "o que fazer?" diante de espaços urbanos que precisam ser revistos - que nos permite conferir importância ao Ciam em relação à construção do campo do urbanismo.

Esse questionamento nos remete à essência do mesmo problema com que se deparou o Ciam no pós-guerra ou Giedión em época anterior: "Quais são as exigências que um urbanista deve atender hoje? Quais são seus objetivos? Qual será sua atitude em face de seu trabalho?" (GIEDIÓN, 1961, p. 742). 
Essas dúvidas também são questionamentos dos urbanistas contemporâneos. São indagações que se fazem presentes todas as vezes que um urbanista é chamado a desempenhar sua atividade. São elas que encaminham a proposta de projeto e revelam as dificuldades nas relações entre o urbanismo e a cidade, entre o urbanismo e a sociedade e, enfaticamente, entre o urbanista e seu objeto de trabalho (MEYER, 2007). No entanto, são perguntas que até hoje permanecem sem resposta, apesar das inúmeras tentativas de respondê-las.

Contudo, do ponto de vista da construção do campo do urbanismo, são as tentativas de se obter respostas que constroem o saber urbano. E é sob esse aspecto que o método do $8^{\circ}$ Ciam se torna relevante. Ele é produto de uma tentativa.

Ao rever os projetos urbanos concebidos sob a influência de seus princípios, os modernistas incorreram em um processo autocrítico que Ihes permitiu promover uma renovação teórica para tentar construir um instrumental que pudesse reparar os desvios de sua arquitetura, tais como: a monotonia da paisagem, a quantificação exagerada das necessidades humanistas, a criação dos espaços de ninguém, a monumentalidade dimensional, o conflito entre o "bem-estar social" mediado pelo Estado e a sociedade capitalista, o descaso com os centros históricos, a desconsideração da importância da história, a forma urbana fechada e utópica, a dispersão social, a estética excludente e a ausência da subjetividade dos arquitetos e urbanistas.

Desse processo autocrítico emergiu o principal engano do Ciam: acreditar no desenho e desprezar a substância eminentemente social da construção da cidade. Mas foi através desse mesmo processo que o Ciam encontrou um caminho para colaborar com a construção do campo urbanístico:

- Reafirmou a importância dos aspectos sociais e simbólicos do ambiente construído;

- Recolocou a arquitetura em sua real dimensão, demonstrando que a essência da atividade arquitetônica consiste em servir ao homem em um plano de ordem público, econômico e sociológico;

- Explicitou o verdadeiro papel do urbanista ao revelar que a essência da atividade urbanística consiste em confrontar sua prática com a teoria.

Hoje, diante de tais dificuldades, como à época do Ciam, fica claro que o modo de construir a cidade também precisa ser revisto, contanto que se reconheça como elemento fundamental da atividade urbanística a necessidade de "ter uma concepção da vida tal como transcorre em nosso tempo" (GIEDIÓN, 1961, p. 744). Significa dizer que o principal ao planejar uma cidade é procurar conhecer as exigências de sua sociedade, reencontrar seus objetivos e estabelecer novos procedimentos em face de um novo desempenho. Estas são ações legítimas do urbanismo no tratamento dos assuntos urbanos. Questionar a forma como são executadas e sempre rever seus resultados constitui o caminho que conduz ao aperfeiçoamento do saber urbano. Como em 1951, deve prevalecer, em suma, a consciência de que o papel do urbanista é dar forma à síntese dialética do complexo campo cultural de que somos parte, é criar um ambiente que expresse a realidade e os problemas de nossos dias (ROGERS in SERT, 1955, p. 71). 


\section{Referências}

BRAZ, Ângela. Do projeto à realidade. 2004. Dissertação (Mestrado em Desenvolvimento Urbano), Universidade Federal de Pernambuco, Recife.

CURY, Isabelle (Org.). Cadernos de Documentos n. 3: cartas patrimoniais. Brasília: Iphan, 1995.

CHOAY, Françoise. Destinos da cidade europeia: séculos XIX e XX. In: Cidades: desenhos, desejos e destinos. Salvador: FUFBa, Revista Rua, n. 6, p. 8-21, jul./dez. 1996.

CHOAY, Françoise. O urbanismo, utopias e realidades: uma antologia. 6. ed. São Paulo: Perspectiva, 2007. (Coleção Estudos 67)

HALL, Peter. Cidades do amanhã: uma história intelectual do planejamento e do projeto urbanos no século XX. São Paulo: Perspectiva, 2002.

HUYSSEN, Andréas. Seduzidos pela memória. Rio de Janeiro: Aeroplano, 2000.

FRAMPTON, Kenneth. História crítica da arquitetura moderna. 3. ed. Tradução Jefferson Luís Camargo. São Paulo: Martins Fontes, 2003.

GOMES, Marco Aurélio Filgueiras (Org.). Urbanismo na América do Sul: circulação de idéias e constituição do campo, 19201960. Salvador: EDUFBA, 2009.

GIEDIÓN, Siegfried. Arquitetura y comunidad. 2. ed. Buenos Aires: Nueva Visión, 1958.

GIEDIÓN, Siegfried. Espacio, tiempo, arquitectura. Barcelona: Gráfica Delfin, 1961.

GUTIÉRREZ, Victoriano Sainz. Otro modo de concebir el urbanismo. La trayectoria del morfologismo en Italia y Francia. Disponível em: <http://www.unav.es/arquitectura/ccc/cccmorfologismo.pdf>. Acesso em: 15 ago. 2007.

JACKSON, Frank. Sir Raymond Unwin, architect planner and visionary. London: A. Zwemmer, 1985.

MENEGUELLO, Cristina. O coração da cidade: observações sobre a preservação dos centros históricos. Disponível em: <http:// www.revista.iphan.gov.br/matéria.php. Acesso em: 22 maio 2007.

MEYER, Regina M. Prosperi. Urbanismo à procura do espaço perdido. Revista Arquitetura. Disponível em: <http://www.usp. br/revistausp/n5/regina>. Acesso em: 15 maio 2007.

MUNFORD. Eric Paul. The Ciam discourse on urbanism, 19281960. Cambridge: The Mit Press, 2002.

REGO, Renato Leão. O desenho urbano. Acta Scientiarum. Maringá, v. 23, n. 6, p. 1569-1577, 2001. Disponível em: <http:// www.ppg.uem.br/Docs/ctf/Tecnologia/2001/33_206_01>. Acesso em: 11 maio 2007.

SAMPAIO, Antônio Heliodório Lima. (Outras) Cartas de Atenas: com textos originais. Salvador: Quarteto, 2001.

SEGAWA, Hugo; DOURADO, Guilherme Mazza. Mário Pedrosa urbanista. Risco - Revista de Pesquisa em Arquitetura e Urbanismo, Programa de Pós-graduação em Arquitetura e Urbanismo da 
Escola de Engenharia de São Carlos, EESC-USP, São Paulo, v. 1, n. 2, p. 63-66, $1^{\circ}$ semestre de 2003. Disponível em: http://www. arquitetura.eesc.usp.br/revista_risco/Risco1-pdf/ref2_risco1.pdf Acesso em: 27 ago. 2009.

SERT, José Luis. Can our cities survive? Cambridge: Harvard University Press, 1942.

SERT, José Luis; ROGERS, Ernesto N.; TYRWHITT, Jacqueline. EI corazón de la ciudad: por una vida más humana de la comunidad (Ciam 8, Hoddesdon, 1951). Barcelona: Hoepli S. L., 1955.

SERRE, Maria Piera (Org.). Gustavo Giovannoni: riflessioni agli iniza del XXI século. Roma: Bonsignori, 2005.

VENTURINI, Roberto; BROW, Denise S.; IZENOUR, Steven. Aprendendo com Las Vegas. São Paulo: Cosac \& Naify, 2003.

\section{Endereço para correspondência}

Angela Martins Napoleão Braz e Silva

Rua Theodomiro Baptista, 126, BI. B, apto 302, Rio Vermelho

41940-320 - Salvador - BA

angelanapoleaobraz@gmail.br

abraz@ufpi.br 
